\title{
Bereavement and palliative care: A public health perspective
}

\author{
Bruce Rumbold \& Samar Aoun
}

A renewed interest in bereavement was first a precursor, and then an accompaniment, to the hospice movement that formed in late 1960s (1). Reviews of bereavement studies from the mid-1950s (2) tell the story of an evolving interest in the psychology of bereavement, fuelled largely by clinical encounters of psychiatrists and then psychological counsellors with grieving people, predominantly women. Discussing death and its impact on survivors led in due course to interest in the experience of dying, giving further impetus to the fledgling hospice movement.

Investigating connections between the way people died and ways others mourned those deaths followed (3). The majority of these investigations took place within a counselling framework, to the extent that counselling is now seen as the normative approach to the 'problem' of bereavement, and knowledge of bereavement is still largely shaped by data from clinical encounters. Some social investigation of the experience of grief beyond the consulting room has been carried out, and a social dimension has been introduced to counselling approaches with the concept of "continuing bonds" $(4,5)$. Overall, however, we know more and more about bereavement as it is engaged by professionals, usually professionals connected with health services through their training if not employment, but we still know surprisingly little about bereavement as it is lived out in everyday life.

While bereavement studies and palliative care may have grown up together, and continue to join forces within palliative care service models, there is one respect in which the two streams differ, and that is in public health awareness. There has been an increasing emphasis upon seeing palliative care in the context of end of life services across whole populations, demonstrated in the population-based studies of Belgium's End of Life Care Research Group (6) and the WHO Public Health Palliative Care Centre of Excellence programs in Barcelona (7) and Kerala (8). All these in various ways seek to understand the relevance of a hospicebased palliative care model to the diverse experiences of dying in contemporary society. There is however no corresponding public health investigation of bereavement. Yet public health approaches to palliative care need to be accompanied by public health approaches to bereavement care if we are to develop relevant, coherent and comprehensive end of life care policies and practices.

\section{Bereavement and loss}

Almost everyone in every society has experience in living with and overcoming loss. Not all the strategies developed as a result of such experiences transfer readily or appropriately to bereavement. But in general individuals and their communities have a reservoir of relevant experiences and strategies upon which to draw. We are belatedly realising that the recent emphasis upon counselling as a normative professionalised response to bereavement tends to discount or ignore these resources built up within local networks. It causes many people to feel that, rather than looking first to their own resources, they need to look for 
professional help. Further, framing bereavement as requiring professional attention becomes self-fulfilling in the sense that bereavement becomes understood as a problem to be solved rather than an experience to be engaged. Only now are data emerging to remind us that this professionalised perception is not necessarily the case, and that early intervention from a clinical standpoint may in fact be unhelpful, even aversive (9). Offering professional support to all bereaved people is not effective for the following reasons (10):

- Early intervention may disrupt the natural course of grieving, as emotional, social and practical consequences of the loss still need to take their natural course

- Interventions could interfere with support networks, prompting friends and family to withdraw

- Bereaved people may be prevented from finding their own solutions

This of course is not to say that counselling interventions are unwarranted, or that complicated mourning does not exist - there is clear evidence that psychotherapy may be of benefit to bereaved individuals experiencing complications (11). Rather, we are pointing out that the existence of complications for some people does not mean that strategies appropriate to complicated grief should necessarily shape all responses to grief. The dilemma we face in bereavement care today is that our perceptions and strategies for all are largely shaped by the complications that can arise for some, and we pay correspondingly less attention to the experience and resources used by the majority, those who learn to live with their loss.

\section{Clinical services compared with public health approaches}

Clinical practice, quite properly, is set up to cope with potential complications to whatever condition is treated: best practice assesses the situation and uses strategies that will meet the needs being presented. This implies a certain level of 'defensive practice': responding to need involves clinicians not only in providing treatment but also in refusing or deflecting demands for services when these services are deemed not to be warranted.

Applying such an approach to bereavement is not however straightforward. Complications of bereavement are not evident from the beginning: they arise when responses that are usual in the early phase of bereavement are prolonged well beyond the time when could be expected to abate. There are still no reliable predictive tests as to whether acute bereavement will persist and become persistent or chronic bereavement. And even this way of considering bereavement continues to construct it as a problem.

The National Institute for Clinical Excellence in the UK has proposed a 3 tiered approach to bereavement care and offering support to different groups of bereaved people (12). Family and friends can offer support and information to those with normal grief; volunteers and self-help groups if trained can give nonprofessional support for bereaved people who need more reflection on their loss (second group). Only the third group with more complex needs that might lead to complicated grief would need professional support and specialist interventions. 
Our public health model (13), rather than organise its strategies around the potential for complications, takes into account the fact that most people manage to live with and through bereavement without developing mental health problems. The resources available to them in their everyday lives are sufficient to meet their needs. Preliminary findings of a pilot study (14) support this, despite the small sample size. The analysis of the demographic characteristics, experience and impact of caring and bereavement, and satisfaction with support received from a variety of services revealed differentiated experiences and needs that align with the expectation of low, moderate, and high need, as articulated in the public health model. The model also suggests an explanation of why complexity may not be immediately identifiable. It may be the failure, or absence, of these ordinary resources that contributes to persistent or prolonged grief or complex reactions to the event of loss. If so, trying to move therapeutic responses upstream, introducing counselling earlier for people intuited to be 'at risk', may not be the best solution: better if possible to mobilise the type of support which is missing from these individuals' personal and social networks.

\section{A revival of clinical treatment?}

The range of community programs and resources that address grief, loss and bereavement is increasing, but the capacity of health services to access and utilise such resources is limited both by protocol and mind-set. Health services are used to referring within professional service networks: referrals into the community are less common, in part because they seem less accountable in a risk-aversive system. Risk-aversion however constellates another form of risk that, in the absence of other viable and tested options, or a lack of clear referral strategies, the fall-back position for health services becomes their in-house response. The easy option for health services today is to respond with direct services to any requests for care, a process that expresses and reproduces medicalization: bereaved people are thereby delivered into the hands of strangers rather than reconnected with friends and families. DSM-5, published in May 2013, seems likely to reinforce such practices. By removing bereavement as an exclusion for a diagnosis of major depressive disorder and adjustment disorder, the likelihood that normal bereavement will be subsumed into psychiatric categories seems increased (15-18). DSM-5's proposal of a chronic persistent grief disorder appears to be intended as a category to capture complicated or prolonged grief, but it lacks even the theoretical framing that has been developed for these latter conditions. 'Chronic persistent grief' could thus become a diagnosis of convenience to be used by therapists who opt not to frame the bereaved person's response within other diagnostic categories. With the implicit reframing of bereavement unleashed by DSM-5, we need more than ever a comprehensive and systemic framework for bereavement care.

\section{Contemporary issues}

Currently bereavement care within palliative care is being reviewed worldwide. Rather than offer a universal grief support program, as was once the case, palliative care programs are attempting to target need so that scarce resources are used more effectively. One difficulty in making the shift is that we have a well-established practice of grief counselling, but other non-professional or 
community-based strategies are less documented or evaluated and thus, it appears, neglected as lacking the evidence base of professionalised responses. Services are equipped to provide support at higher levels of need, but are less clear about the information, advice and referrals they might make for the majority of their bereaved clients.

The harder, but necessary, response required of palliative care services is to build relationships with local communities and the resources that should be a first level of response. This begins with ensuring that everyday relationships with clients of our services are respectful, realistic and personal, so that clients experience care that will for many be sufficient to allow them to mobilise and use the strategies they already have available to them.

It is instructive to consider how bereavement has been, and continues to be, expressed in society at large. Traditional funeral rituals are often preceded by various informal acts of recognition - placing flowers, toys, bringing gifts of food, placing notices, uploading pictures and tributes on social media sites (19-22). Funeral rituals themselves increasingly incorporate a range of personal reflections, some suggested by the deceased, others by friends and family, juxtaposed with cultural resources that reflect the meaning that person had found in life (23-25). Funerals are then followed by private or semi-public activities such as dividing or scattering ashes (26-27), and often gifts or bequests made in memory of the person who has died. Memorialisation is in fact a powerful contributor to community life (28): the cultural life of most towns and cities is based upon memorials, gifts given in memory of a parent, a spouse, a child, or inherited resources devoted to philanthropy. Some are extravagant - a hospital wing, an endowed scholarship - while others are more modest - a plaque on a favourite park bench, perhaps. Such rituals build solidarity; they are ways of acting that transcend or replace the struggle to find words of comfort. They are activities that reconnect bereaved people with the ongoing life of their community, contributing to the acknowledgement, respect and inclusiveness that Riches and Dawson (29) identify as foundational to effective bereavement support. Such support ideally begins with the community and is mirrored in the support provided by health services. And rather than define bereavement as a problem, they recognise the solace that sorrow can bring (30).

\section{Implications for palliative care services}

This public health perspective has a number of implications for palliative care services. We will focus on two here. First, and foremost, if palliative care services wish to serve the majority of their bereaved clients, they should attend to developing community capacity rather than to providing specialised bereavement services of their own. After all, only a small proportion of the relatives and friends of those who die in specialised palliative care will need specialised bereavement services, just as only a proportion of the relatives and friends of those who die without using palliative care services will require them. But many communities have two sets of bereavement services allocated on the basis of the deceased person's place of death rather than the bereaved person's need. In general, bereaved people need to find support in their local communities, not be drawn back into professionally-organised contexts to receive support, 
while specialist bereavement services would best be accessed through general community programs. Palliative care services should thus resist 'keeping it in the family' thinking and make their contribution through a web of partnerships that extend into the community as well as encompass a range of other health services (31). While palliative care bereavement services are often intended as a strategy for maintaining contact with bereaved clients in order to identify complications if they arise, this is a less than effective screening method. In a nutshell, grief portfolios in palliative care teams should be held by people with qualifications in education or health promotion or community development, not primarily in counselling (although of course counseling skills are a useful adjunct to these other qualifications). Ultimately what matters is that the community owns end of life care, with healthcare professionals advising, supporting, coaching and contributing as required.

Second, end of life care should follow an assets-based approach, not merely attend to deficits. This is entirely consistent with palliative care philosophy with its interest in achieving a 'good death'. It follows that services should seek to facilitate 'good grief'. This is best done by identifying, confirming and supporting the assets people have for caring for themselves and others in bereavement. Services should identify and coach these strengths, expressing confidence in people's ability to make decisions about their own lives and supporting the care they offer, not reinforcing dependence. Services should also support where possible the natural networks that surround people in their everyday lives. This is a change that can be initiated by palliative care services at the point of care. Collaborative care in dying will strengthen these natural networks, but prescriptive care that sidelines natural networks risks disabling their potential for bereavement care $(32,33)$

\section{REFERENCES}

1. Hockley J. The evolution of the hospice approach. In: Clark D, Hockley J, Ahmedzai S, editors. New themes in palliative care. Buckingham: Open University Press; 1997. p. 84-100.

2. Small N. Theories of grief: a review. In: Hockey J, Katz J, Small N, editors. Grief, Mourning and Death Ritual. Buckingham: Open University Press; 2001. p. 19-48.

3. Fulton G, Madden C, Minichiello V. The social construction of anticipatory grief. Social Science and Medicine. 1996:43(9);1349-58.

4. Klass D, Silverman P, Nickman S, editors. Continuing Bonds: New Understandings of Grief. Washington: Taylor \& Frances; 1996.

5. Klass D. Continuing conversations about continuing bonds. Death Studies. 1996: 30;843-58.

6. Cohen J, Deliens L, editors. A public health perspective on end of life care. Oxford: Oxford University Press; 2012.

7. Gomez-Batiste X, Martinez-Muñoz M, Blay C, Espinosa J, Contel JC, Ledesma A. Identifying needs and improving palliative care of chronically ill patients: A community-oriented, population-based, public-health approach. Curr Opin Support Palliat Care. 2012; 6(3):371-8, doi: 10.1097/SPC.0b013e328356aaed.

8. Kumar S. Models of delivering palliative and end of life care in India. Curr Opin Support Palliat Care. 2012; 6(3):371-8, doi: 10.1097/SPC.0b013e3283610255. 
9. Regehr C, Sussman T. Intersections between grief and trauma: Towards an empirically based model for treating traumatic grief. Brief Treatment and Crisis Intervention. 2004:4(3);289-309.

10. Schut H, Stroebe M, van den Bout J, Terheggen M. The efficacy of bereavement interventions: determining who benefits. In: Stroebe M, Hansson R, Stroebe W, Schut $\mathrm{H}$, editors. Handbook of bereavement research: Consequences, coping, and care. Washington, DC: American Psychological Association; 2001. p. 705-727.

11. Currier JM, Neimeyer RA and Berman JS. The effectiveness of psychotherapeutic interventions for bereaved persons: A comprehensive quantitative review. Psychological Bulletin. 2008; 134: 648-61.

12. National Institute for Health Clinical Excellence (UK). Guidance on cancer services: Improving supportive and palliative care for adults with cancer. London: National Institute for Health Clinical Excellence; 2004 [Available from: http://guidance.nice.org.uk/CSGSP/Guidance/pdf/English.

13. Aoun SM, Breen LJ, O'Connor M, Nordstrom C, Rumbold B. A public health approach to bereavement support services in palliative care. Australian and New Zealand Journal of Public Health. 2012:36;14-16.

14. Aoun SM, Breen L, Rumbold B, Howting D. Exploring the Application of the Public Health Model to Bereavement Support. Accepted in the Australian and New Zealand Journal of Public Health.

15. Bryant R. Grief as a psychiatric disorder. British Journal of Psychiatry. 2012:201;9-10.

16. Friedman R. Grief, depression, and the DSM-5. N Engl J Med. 2012:366(20);18557.

17. Rando T, Doka K, Fleming S, Franco MH, Lobb E, Parkes CM, Steele R. A call to the field: Complicated grief in the DSM-5. Omega. 2012:65(4);251-5.

18. Wakefield JC. Should prolonged grief be reclassified as a mental disorder in DSM5? J Nerv Ment Dis. 2012:200;499-511.

19. Walter T. The revival of death. London: Routledge; 1994.

20. Wouters C. The quest for new rituals in dying and mourning: Changes in the we-I balance. Body \& Society. 2002:8(1);1-27.

21. Carroll B, Landry K. Logging on and letting out: Using online social networks to grieve and to mourn. Bulletin of Science, Technology \& Society. 2010:30(5);3419.

22. Walter T, Hourizi R, Moncur W, Pitsillides S. Does the internet change how we die and mourn? Overview and analysis. Omega. 2011:64(4);275-302.

23. Howarth G. Death and Dying: A sociological introduction. Cambridge: Polity Press; 2007.

24. Walter, T. On bereavement: The culture of grief. Buckingham: Open University Press; 1999. .

25. Kellaher L, Prendergast D, Hockey J. In the shadow of the traditional grave. Mortality. 2005:10(4);237-50.

26. Prendergast D, Hockey J, Kellaher L. Blowing in the wind? Identity, materiality, and the destination of human ashes. Journal of the Royal Anthropological Institute. 2006:12(4);881-98.

27. Holloway M, Adamson S, Argyrou V, Draper P, Mariau D. “Funerals aren't nice but it couldn't have been nicer". The makings of a good funeral. Mortality. 2013:18(1); 30-53.

28. Petterson A, Wingren C. Designing a memorial place: continuing care, passage landscapes and future memories. Mortality. 2011:16(1);54-69.

29. Riches G, Dawson P. An intimate loneliness. Buckingham: Open University Press; 2000.

30. Klass D. Sorrow and solace: Neglected areas in bereavement research. Death Studies. 2013:37(7);597-616. 
31 Abel J, Walter T, Carey L, Rosenberg J, Noonan K, Horsfall D, Leonard R, Rumbold B, Morris D. Circles of Care: Should community development redefine the practice of palliative care? BMJ Supportive \& Palliative Care. 2013. doi: 10.1136/bmjspcare-2012-000359

32. Horsfall D, Noonan K, Leonard R. Bringing our dying home: How caring for someone at end of life builds social capital and develops compassionate communities. Health Sociology Review. 2012:21(4);373-82.

33. Horsfall D, Leonard R, Noonan K, Rosenberg J. Working together - apart: exploring the relationships between formal and informal care networks for people dying at home. Progress in Palliative Care. 2013. Doi 10:1179/1743291X12Y.0000000047 